\title{
Insulin pump therapy in children with type 1 diabetes: analysis of data from the SWEET registry
}

\author{
Agnieszka Szypowska ${ }^{1}$ | Anke Schwandt ${ }^{2,3}$ | Jannet Svensson ${ }^{4}$ | Shlomit Shalitin ${ }^{5,6}$ | \\ Roque Cardona-Hernandez ${ }^{7}$ | Gun Forsander ${ }^{8,9}$ | Frida Sundberg ${ }^{9}$ | Carine De Beaufort ${ }^{10,11}$ | \\ David Maahs $^{12}$ | Claudio Maffeis ${ }^{13}$ | Stephen M.P. O'Riordan ${ }^{14}$ | Iveta Dzivite Krisane ${ }^{15}$ | \\ Mauro Scharf ${ }^{16}$ | Sofia Castro ${ }^{17}$ | Maia Konstantinova ${ }^{18}$ | Barbora Obermannova ${ }^{19}$ | \\ Kristina Casteels ${ }^{20,21}$ | Damla Gökşen ${ }^{22}$ | Júlia Galhardo ${ }^{23}$ | Christina Kanaka-Gantenbein ${ }^{24}$ | \\ Birgit Rami-Merhar ${ }^{25}$ | Laszlo Madacsy ${ }^{26}$ | the SWEET Study Group
}

${ }^{1}$ Department of Paediatrics, Medical University of Warsaw, Warsaw, Poland

${ }^{2}$ Institute of Epidemiology and Medical Biometry, ZIBMT, University of UIm, UIm, Germany

${ }^{3}$ German Center for Diabetes Research (DZD), Munich-Neuherberg, Germany

${ }^{4}$ Pediatric Department, Copenhagen University Hospital, Herlev, Denmark

${ }^{5}$ The Jesse $Z$ and Lea Shafer Institute of Endocrinology and Diabetes, National Center for Childhood Diabetes, Schneider Children's Medical Center of Israel, Petach Tikva, Israel

${ }^{6}$ Sackler Faculty of Medicine, Tel Aviv University, Tel Aviv, Israel

${ }^{7}$ Division of Endocrinology and Diabetes, Hospital Sant Joan de Déu., Barcelona, Spain

${ }^{8}$ Institute for Clinical Sciences, Sahlgrenska Achademy, University of Gothenburg, Gothenburg, Sweden

${ }^{9}$ The Queen Silvia Childrens Hospital, Sahlgrenska University Hospital, Gothenburg, Sweden

${ }^{10} \mathrm{DCCP}-\mathrm{Clinique}$ pédiatrique de Luxembourg, Luxembourg, Luxembourg

${ }^{11}$ Department of Pediatric Endocrinology, UZBrussels, Brussels, Belgium

${ }^{12}$ Barbara Davis Center for Childhood Diabetes, University of Colorado Denver Aurora, Colorado, USA

${ }^{13}$ Pediatric Diabetes and Metabolic Disorders Unit \& Regional Center for Pediatric Diabetes, University Hospital, University of Verona, Verona, Italy

${ }^{14}$ Paediatrics Diabetes \& Endocrine Unit, Department of Paediatrics \& Child Health, Cork University Hospital, University College Cork, Cork, Ireland
Background: Intensified insulin delivery using multiple daily injections (MDI) or continuous subcutaneous insulin infusion (CSII) is recommended in children with type 1 diabetes (T1D) to achieve good metabolic control.

Objective: To examine the frequency of pump usage in T1D children treated in SWEET (Better control in Paediatric and Adolescent diabeteS: Working to crEate CEnTers of Reference) centers and to compare metabolic control between patients treated with CSII vs MDI.

Methods: This study included 16570 T1D children participating in the SWEET prospective, multicenter, standardized diabetes patient registry. Datasets were aggregated over the most recent year of treatment for each patient. Data were collected until March 2016. To assess the organization of pump therapy a survey was carried out.

Results: Overall, $44.4 \%$ of T1D children were treated with CSII. The proportion of patients with pump usage varied between centers and decreased with increasing age compared with children treated with MDI. In a logistic regression analysis adjusting for age, gender and diabetes duration, the use of pump was associated with both: center size [odd ratio 1.51 (1.47-1.55), $P<.0001)$ and the diabetes-related expenditure per capita [odd ratio 1.55 (1.49-1.61), $P<.0001]$. Linear regression analysis, adjusted for age, gender, and diabetes duration showed that both $\mathrm{HbA1c}$ and daily insulin dose $(\mathrm{U} / \mathrm{kg} / \mathrm{d})$ remained decreased in children treated with CSII compared to MDI $(P<.0001)$.

Conclusions: Insulin pump therapy is offered by most Sweet centers. The differences between centers affect the frequency of use of modern technology. Despite the heterogeneity of centers, T1D children achieve relatively good metabolic control, especially those treated with insulin pumps and those of younger age.

\section{KEYWORDS}

childhood diabetes, continuous subcutaneous insulin infusion, CSII, MDI, multiple daily injections 
${ }^{15}$ Children's University Hospital Children's Endocrinology Centre, Riga Stradins University, Riga, Latvia

${ }^{16}$ Pediatric Endocrinology, Hospital Nossa Senhora Das Graças, Brazil

${ }^{17}$ Child and Young Department, APDP-Diabetes, Lisbon, Portugal

${ }^{18}$ Medical University-Clinic of Endocrinology, Diabetes and Genetics, Sofia University Pediatric Hospital, Sofia, Bulgaria

${ }^{19}$ Department of Pediatrics, University Hospital Motol and 2nd Faculty of Medicine, Charles University in Prague, Prague, Czech Republic

${ }^{20}$ Department of Pediatrics, University Hospitals Leuven, Leuven, Belgium

${ }^{21}$ Department of Development and Regeneration, KU Leuven, Belgium

${ }^{22}$ Faculty of Medicine Pediatric Endocrinology and Diabetes, Ege University, İzmir, Turkey
${ }^{23}$ Unit of Pediatric Endocrinology and Diabetes, Hospital Dona Estefânia, Lisbon, Portugal

${ }^{24}$ Diabetes Center, Division of Endocrinology, Diabetes and Metabolism First Department of Pediatrics, Medical School National and Kapodistrian University of Athens-Greece "Aghia Sophia" Children's Hospital, Athens, Greece

${ }^{25}$ Department of Pediatrics and Adolescent Medicine of Medical University of Vienna, Vienna, Austria

${ }^{26}$ First Department of Pediatrics, Semmelweis University, Budapest, Hungary

Conflict of Interest: The authors declare no potential conflict of interests.

Corresponding Author: Agnieszka Szypowska Assoc. Prof., MD, PhD, Medical University of Warsaw, Department of Paediatrics, Żwirki i Wigury 63A, 02-091 Warsaw, Poland (agnieszka.szypowska@gmail.com).

\section{1 | INTRODUCTION}

Many clinical trials have demonstrated that tight blood glucose control reduces the risk of developing microvascular diabetes complications in all patients with type 1 diabetes (T1D). The beneficial effects of reducing cardiovascular disease, retinopathy, nephropathy, and neuropathy are well documented in the DCCT-EDIC study. ${ }^{1,2}$ In order to reduce these long-term effects of hyperglycemia, glucose control should be optimized as early as possible in the course of type 1 diabetes. $^{3}$

An intensified insulin regimen is necessary in T1D patients to achieve near-normal glucose control. However, only a relatively small percentage of patients achieve these glycemic targets. ${ }^{4}$ Continuous subcutaneous insulin infusion (CSII) is a very effective treatment modality, which is safe and widely used in children and adolescents with T1D. There are many benefits for CSII therapy in children and adolescents such as: optimum blood glucose control, reduction of recurrent/severe and disabling hypoglycemia and improved quality of life. ${ }^{5}$ Insulin pump therapy allows a greater flexibility in insulin dosing and meal planning, when compared with multiple daily injections (MDI). ${ }^{6,7}$ Meta-analyses demonstrate a reduction in glycated hemoglobin A1c (HbA1c) and severe hypoglycemia with CSII therapy compared to $\mathrm{MDI}^{8}$

Following the evidence-based demonstrations of the benefits of CSII therapy, the first international consensus statement of insulin pump indications and practice in children was created in 2007.9

Insulin pump therapy in the pediatric age group has markedly increased in the last decade (2007-2016). However, use of CSII remains limited in some European countries. The main reasons are a lack of funding by National Healthcare Insurance Systems, low number of trained physicians to deliver insulin pump therapy and a lack of trained diabetes educators. ${ }^{10}$

We hypothesized that children with T1D treated in SWEET (Better control in Paediatric and Adolescent diabeteS: Working to crEate CEnTers of Reference) centers with CSII had a better metabolic control than those using MDI. The aims of this study are: to examine the frequency of pump usage in T1D children treated in SWEET centers and to compare the cross-sectional metabolic control between patients treated with CSII vs. MDI.

\section{2 | METHODS}

The analysis is based on data from SWEET, a prospective, multicenter, standardized diabetes patient registry. Currently, 48 diabetes care institutions are participating in the SWEET project. For the data collection, the SWEET project users use a heterogeneous environment: Centers may use DPV ("Diabetes-Patienten-Verlaufskodumentation," https://sweet.zibmt.uni-ulm.de/software.php), DIAMAX, data download from of existing registries or may use own local databases to collect data. All centers longitudinally record demographic and clinical data of patients with diabetes and transfer anonymized local data to the SWEET database twice yearly. To increase the quality of data, inconsistent/implausible data are reported back for verification or correction after each data upload. Patients' data are collected in SWEET database at the Institute of Epidemiology and Medical Biometry, University of UIm, UIm, Germany. The current analysis involved 19 European countries (39 centers) and 7 countries outside Europe.

Until March 2016, 28713 patients with diabetes were available in the database. Datasets with missing age, sex or diabetes duration were excluded. For the present analysis, patients with type 1 diabetes, aged $0-18$ y and with a diabetes duration $\geq 1$ y were included. The exclusion criterion was missing insulin therapy (Figure 1). Datasets were aggregated over the most recent year of treatment for each patient. Three SWEET centers were excluded from analysis due to incomplete data. The final cohort available for analysis was $\mathrm{n}=16570$ children with type 1 diabetes treated in 46 centers.

Diabetes control was assessed by glycated hemoglobin value (HbAlc), which was measured locally in each center. In order to adjust for differences between laboratories, multiple of the mean (MOM) method was used to mathematically standardize HbA1c values to the reference range of the Diabetes Control and Complications Trial [DCCT, 21-43 mmol/mol (4-6\%)]. ${ }^{11}$ Insulin pump usage was defined as at least one visit with pump therapy. Body mass index standard deviation score (BMI-SDS) was measured using the World Health Organization (WHO) charts. $^{12}$

Further analysis was performed in three subgroups according to age: $0-<6,6-<12,12-18$ y. Diabetes duration was grouped into $<5$ and $\geq 5$ y. Center size was defined as the number of patients in each center. 
Severe adverse events were not evaluated due to incomplete data concerning number of severe hypoglycemia [34\% (5618/16 570) of missing data] and diabetic ketoacidosis episodes [60\% (9870/ 16570 ) of missing data]. Moreover, no data regarding ethnicity of the participants were available in the SWEET database.

Children were divided into two groups depending on the method of insulin therapy: insulin pump (CSII) or MDI. We evaluated the frequency of insulin pump usage in the different age groups and compared outcomes of diabetes control between children using insulin pump therapy or MDI.

In order to collect data on the organization of pump therapy in SWEET centers, each center was invited to complete an online survey. The questions included were the following: presence of National Pump Registry, reimbursement of insulin pump therapy, initiation and discontinuation of pump treatment and 24-h access to a pediatric diabetes team member. Participants were able to mark only one answer for each question. The survey was completed by 32 centers (67\%) and the results are seen in Table 1.

\section{1 | STATISTICAL ANALYSIS}

Wilcoxon or $\chi^{2}$-tests were performed to compare the demographic characteristics and clinical outcomes between patients using CSII and MDI therapy. The results are presented as median and interquartile range (25 and 75 percentile), or numbers and percentages. Linear regression model adjusted for age, gender and diabetes duration was run to compare clinical outcomes between CSII and MDI groups. In the linear regression analysis the mean and the standard error (SE) were used to describe the differences. The Spearman rank correlation and logistic regression model adjusted for center size and age, sex and diabetes duration was used to analyze if center size had an impact on pump use. The link between countries' national health care spending per person with diabetes (expressed in US dollars, $R=2$ ) and use of pumps in children was evaluated using data from the IDF Diabetes Atlas $2015^{13}$ derived from the methods described by Zhang et al. ${ }^{14}$ Analyzing this link, we used Spearman rank correlation and logistic regression model adjusted for country's diabetes-related health care spending per person, age, sex, and diabetes duration. For logistic regression analysis, results are presented as an odds ratio with 95\% confidence intervals. Statistical analysis was performed using Statistical Analysis Software 9.4 (SAS, SAS Institute Inc., Cary, NC, USA). $P$-values $<.05$ were considered statistically significant.

\section{3 | RESULTS}

The current analysis included 16570 participants (51.5\% male). Median age was "14 (Quartile 1; Quartile 3:10.6; 16.7) y", diabetes duration "5.3 (3.0; 8.5) y", HbA1c "7.8 (7.1; 8.8)\% [62 mmol/mol (54; 73) $\mathrm{mmol} / \mathrm{mol}]$ ", BMI-SDS "0.55 (-0.1; 1.19)" and daily insulin dose "0.87 (0.68; 1.1) U/kg/d". We included 12839 (77\%) participants from European countries and 3731 (23\%) children from countries outside Europe.

Results showed that $44.4 \%$ of T1D children and adolescents were treated with CSII (varying from 0\% to $90 \%$ per center). There

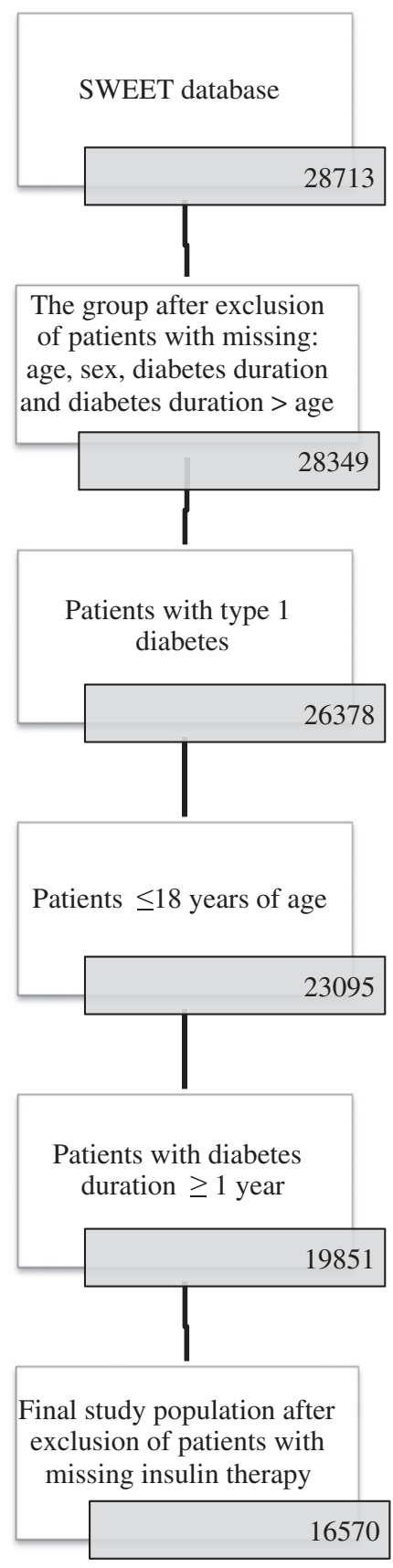

FIGURE 1 Selection of study population

was comparable percentage of pump users in European countries (45.8\%) and in countries outside Europe (39.3\%).

Center size did not influence pump use in the full group ( $r=0.25, P=.088$ ). In a logistic regression analysis adjusting for age categories, gender and diabetes duration categories, the use of pump was associated with center size with an estimated odd ratio 1.51 (1.47-1.55), $P<.0001$. This means that for every 500 patient increase in center size, the probability of a child being on a pump increases by $51 \%$. There was no significant correlation between proportion of CSII users in each center and $\mathrm{HbA1c}(r=-0.26, P=.084)$.

For the countries represented in this cohort, the mean diabetesrelated expenditure per person with diabetes per country in 2015 ranged from 95 to 1168 USD. When using a logistic regression adjusting for demographics, pump usage was associated with the 
TABLE 1 Survey results of the organization of pump therapy in SWEET centers.

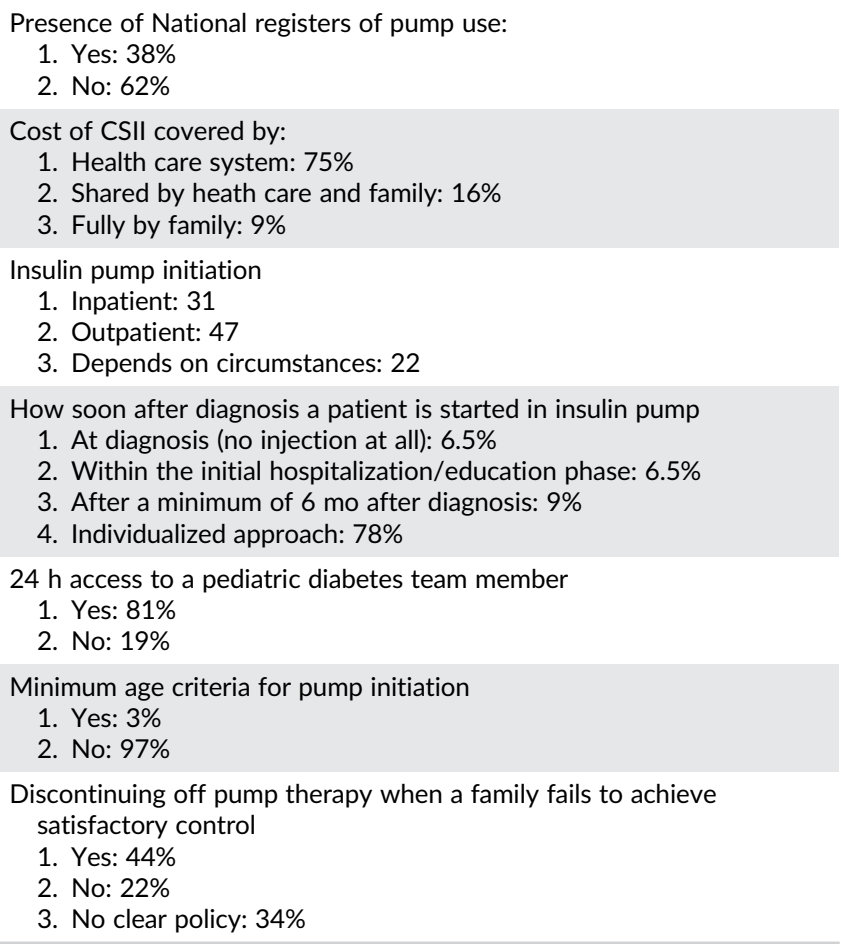

Abbreviations: CSII, continuous subcutaneous insulin infusion; SWEET, Better control in Paediatric and Adolescent diabeteS: Working to crEate CEnTers of Reference

diabetes-related expenditure per capita [estimated odd ratio 1.55 (1.49-1.61), $P<.0001$ ] such that for every 4000 USD increase in spending per capita, the probability of use of pump therapy increased by $55 \%$ (Figure 2 ).

Comparison made between children in different age groups, treated with MDI or CSII therapy, are depicted in Table 2. The frequency of pump use decreased with increasing age $(52 \%$ in children aged $0-<6$ y, $49 \%$ in youth aged $6-<12 y$, and $42 \%$ in patients $12-18 \mathrm{y}$, $\left.\chi^{2}=89.9, P=.0001\right]$. In the entire database there was no sex-related difference in pump use.

In our sample, pump users were younger than injections users [CSII: $13.5(10 ; 16.3)$ y vs MDI:14.4 (11; 17) y, $P<.0001$ ] and had longer diabetes duration [CSII: $5.9(3.5 ; 8.9)$ vs MDI: $4.9(2.8 ; 8) \mathrm{y}$, $P<.0001]$.

The unadjusted HbA1c levels in the CSII users "7.7 [7; 8.5]\%, [60.7 $(53 ; 69) \mathrm{mmol} / \mathrm{mol}]$ " was significantly lower than in the MDI users "8.0 [7.2; 9.1]\%, [63.9 (55; 76) $\mathrm{mmol} / \mathrm{mol}]$ ", $P<.001$ and $\mathrm{HbA1c}$ was lower in all age groups using CSII (Figure 3). Linear regression model analysis, adjusting for age, gender and diabetes duration showed that $\mathrm{HbA} 1 \mathrm{c}$ remained higher in children treated with MDI compared to CSII $(P<.0001)$. Similar results were shown in linear regression analysis adjusting for gender and diabetes duration in age-related subgroups. In all age groups, HbA1c was higher in children treated with MDI compared to CSII $(P<.0001)$.

Children using CSII therapy used lower total daily insulin dose compared to youth treated with MDI [CSII: $0.83(0.66 ; 1.02) \mathrm{U} / \mathrm{kg} / \mathrm{d}$ vs MDI: $0.9(0.7 ; 1.13) \mathrm{U} / \mathrm{kg} / \mathrm{d}, P<.0001)$ and daily insulin dose was lower in both groups of youth $6-<12$ y and $12-18$ y old treated with
CSII (Figure 3). In a linear regression model adjusting for age, gender and diabetes duration, children treated with MDI had higher daily insulin dose $(\mathrm{U} / \mathrm{kg} / \mathrm{d})$ than subjects using CSII $(P<.0001)$.

The unadjusted BMI-SDS was higher in MDI group " $0.51(-0.14$; 1.18)" compared to CSII "0.58 [-0.05, 1.2]", $P=.000$. The BMI-SDS was higher only in children with CSII and 6->12 y of age (Figure 3). Linear regression analysis adjusting for diabetes duration showed a similar BMI-SDS in both treatment groups $(P=0.399)$.

\section{4 | DISCUSSION}

Current results showed that insulin pump therapy was used in $44.4 \%$ children aged 0-18 y treated in the SWEET centers. The data represents only the frequency of pump therapy in the SWEET centers, and does not necessarily reflect the management of diabetes by country. Our survey showed that national data on pump use are present only in $38 \%$ of countries represented in our SWEET group. Owing to lack of national data, the analysis of an overall use of CSII in SWEET countries was not possible.

The prevalence of CSII therapy usage has increased in many countries, but there are still differences in CSII usage among countries. ${ }^{10}$ The overall use of insulin pumps in patients $0-18$ y was $74 \%$ (2011) in Slovenia, ${ }^{7}$ and 58-65\% (2015) in United States. ${ }^{15}$ The data from three large registries of pediatric type 1 diabetes patients analyzed in 2015 showed that insulin pump was used by: $41 \%$ of children in the German/Austrian Prospective Diabetes Follow-up Registry (DPV), $47 \%$ of youth in the US T1D Exchange (T1DX) and $14 \%$ of children in the English/Welsh National Paediatric Diabetes Audit (NPDA). ${ }^{16}$ Data from the Swedish National Diabetes Register reported that in 2013 one out of every four women and one out of every five men used insulin pump treatment. Over half of all Swedish children with T1D are treated with CSII. ${ }^{17}$ The percentage of Danish children on CSII increased to approximately $50 \%$ in $2011 .{ }^{18}$ French national survey performed in 2007 , which represented $60-75 \%$ of the national estimated population of T1D children aged 0-18 y, showed that $15 \%$ of children used insulin pump. ${ }^{19}$

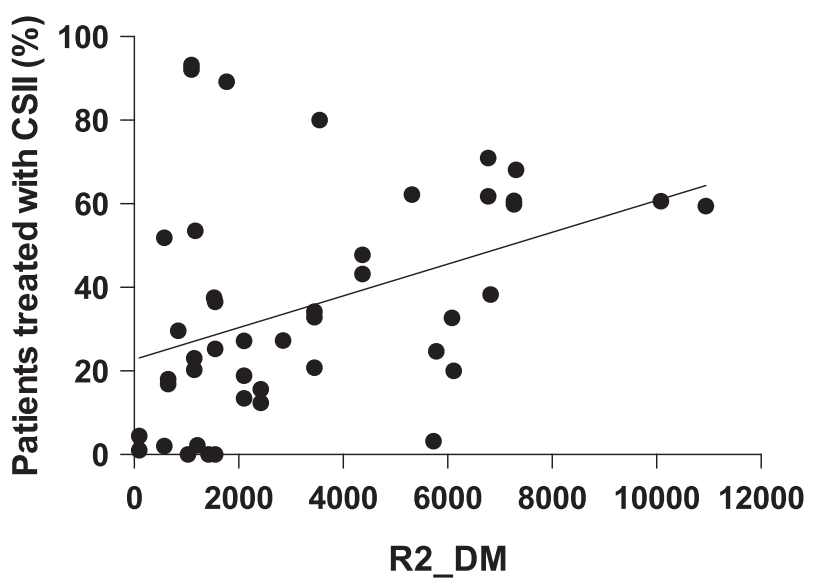

FIGURE 2 Correlation between proportion of patients treated with continuous subcutaneous insulin infusion (CSII) in each center and a country's diabetes related health care spending per person with diabetes expressed in US dollars (R2_DM). 
TABLE 2 Comparison between children in different age groups treated with MDI or CSII therapy. ${ }^{1}$

\begin{tabular}{|c|c|c|c|c|c|c|c|c|c|}
\hline \multirow[b]{2}{*}{$\begin{array}{l}\text { Type of insulin } \\
\text { therapy }\end{array}$} & \multicolumn{3}{|l|}{$0-<6 y$} & \multicolumn{3}{|l|}{$6-<12 y$} & \multicolumn{3}{|l|}{$12-18 y$} \\
\hline & $\begin{array}{l}\text { MDI } \\
\text { median } \\
\text { [Q1;Q3] }\end{array}$ & $\begin{array}{l}\text { CSII } \\
\text { median } \\
\text { [Q1;Q3] }\end{array}$ & $\begin{array}{l}P \\
\text { value }\end{array}$ & $\begin{array}{l}\text { MDI } \\
\text { median } \\
\text { [Q1;Q3] }\end{array}$ & $\begin{array}{l}\text { CSII } \\
\text { median } \\
\text { [Q1;Q3] }\end{array}$ & $\begin{array}{l}P \\
\text { value }\end{array}$ & $\begin{array}{l}\text { MDI } \\
\text { median } \\
\text { [Q1;Q3] }\end{array}$ & $\begin{array}{l}\text { CSII } \\
\text { median } \\
\text { [Q1;Q3] }\end{array}$ & $\begin{array}{l}P \\
\text { value }\end{array}$ \\
\hline Female/male & $184 / 251$ & $231 / 233$ & .049 & $1193 / 1265$ & $1165 / 1193$ & .582 & $3054 / 3267$ & $2217 / 2290$ & .582 \\
\hline Diabetes duration $(y)$ & $2.1[1.5 ; 3.1]$ & $2.2[1.5 ; 3.2]$ & .582 & $3.6[2.1 ; 5.6]$ & $4.7[2.9 ; 6.7]$ & .0001 & $5.9[3.4 ; 9.4]$ & $\begin{array}{c}7.3[4.6 ; \\
10.5]\end{array}$ & .0001 \\
\hline $\begin{array}{l}\text { Daily insulin dose } \\
\text { (U/kg/d) }\end{array}$ & $\begin{array}{l}0.73 \\
{[0.59 ; 0.90 .}\end{array}$ & $\begin{array}{l}0.72 \\
{[0.58 ; 0.86 .}\end{array}$ & .471 & $\begin{array}{l}0.83 \\
{[0.66 ; 1.02 .}\end{array}$ & $\begin{array}{l}0.76 \\
{[0.61 ; 0.91 .}\end{array}$ & .0001 & $\begin{array}{l}0.95 \\
{[0.75 ; 1.18 .}\end{array}$ & $\begin{array}{l}0.89 \\
{[0.71 ; 1.08 .}\end{array}$ & .0001 \\
\hline BMI-SDS & $\begin{array}{l}0.79 \\
{[0.21 ; 1.45 .}\end{array}$ & $\begin{array}{l}0.85 \\
{[0.34 ; 1.51 .}\end{array}$ & .143 & $\begin{array}{l}0.45 \\
{[-0.14 ; 1.14}\end{array}$ & $\begin{array}{l}0.54 \\
{[-0.05,1.16}\end{array}$ & .023 & $\begin{array}{l}0.52 \\
{[-0.16 ; 1.19}\end{array}$ & $\begin{array}{l}0.57 \\
{[-0.09 ; 1.17}\end{array}$ & .103 \\
\hline
\end{tabular}

Abbreviations: BMI, body mass index standard deviation score; CSII, continuous subcutaneous insulin infusion; MDI, multiple daily injections; n.s., not significant.

${ }^{1}$ Given are median with quartile or proportions.

Different factors may influence frequency of pump use in a center. Insulin pump therapy is more expensive than injections. ${ }^{20}$ Therefore, socioeconomic status of families influences the choice of the method of diabetes management in T1D children, especially when there is inadequate or no reimbursement of these devices by national healthcare systems or insurance companies. ${ }^{5,21}$ Our survey showed, that in one third of the centers, costs of CSII therapy are shared by insurance and family or fully covered by family. Moreover, we noted a significant correlation between the proportion of pump users in each center and the diabetes-related health care expenditure per person with diabetes per country. The association between low socioeconomic factors and low frequency of CSII usage was confirmed by other research. ${ }^{22}$ In T1D therapy, systematic reviews of costeffectiveness showed a superiority of CSII over MDI. CSII therapy was associated with an improvement in both global life expectancy and quality-adjusted life expectancy. This was achieved by a decrease in $\mathrm{HbA1c}$ and by a lower number of hypoglycemia episodes in this group. ${ }^{23}$

Our results indicate differences between centers. The correlation did not show any impact of center size on pump usage, but after adjustment for age, sex and diabetes duration we noted that insulin pump therapy was more often used in larger centers. Potential reasons for lower CSII usage in smaller sized center may include organization of diabetes care, insufficient number of physicians specialized in pump therapy or low number of trained diabetes educators. ${ }^{24}$. However, in France no significant variation in the rate of CSII was observed according to the size of the centers, although the frequency of pump use remained extremely variable, ranging from 1.3 to $53 \%$ of T1D children. ${ }^{19}$ Diabetes education of T1D children and their families is an essential part of diabetes care with effects on diabetes outcome. $^{25}$ It is well known from clinical practice that education and training for patients using CSII therapy is more time consuming, compared to education for those using MDI and this influences work organization in diabetes centers. The results of our survey also emphasize individual approach to pump therapy and work organization in different centers. As seen in Table 1 most centers use an individual approach when starting pump, and the majority of pump starts are based in the outpatient clinic. A $24 \mathrm{~h}$ hotline with access to experts in pump therapy is common, whereas guidelines to discontinue insulin pump therapy in non-compliant patients was limited. Ideally multidisciplinary teams supporting pump users, should contain a critical mass of staff (doctors, nurses, dieticians, and diabetes educators) with appropriate ongoing education in CSII therapy. ${ }^{26}$ Our results should be taken with caution because we have not performed any in depth analysis assessing differences in the organization of work in diabetes centers.

The age-related frequency of CSII use differs across countries. Pump therapy is commonly used in children diagnosed before $6 \mathrm{y}$ of age and is associated with better long-term metabolic control. ${ }^{27}$ In our group, CSII therapy was more frequently used in the youngest children less than 6-y-old (52\%), than in teenagers over 12 y (42\%). Similar results were reported in the DPV register. ${ }^{16}$ In this study, $74 \%$ of children less than 6-y-old received insulin pump therapy, compared with $35-40 \%$ of older participants. The highest frequency of pump use in the youngest children was also noted in the NPDA register. ${ }^{15}$ Conversely, the highest frequency of pump users was shown in teenagers in the T1D register. ${ }^{16}$ Observed differences may indicate that different government funding arrangements for insulin pumps (or diabetes-related health care expenditure), may play a significant role in those who are offered pump therapy vs those who are not.

Our results showed no gender-related difference in pump use but further subgroup analysis indicated statistically lower use of insulin pump in boys less than 6-y-old. One may speculate that young boys are busier than girls and they may be inclined to remove infusion sets during vigorous physical activities. The parents may also think these young boys cannot cope with a pump before they try it. Interestingly other studies also noted that boys were treated with a pump less often compared to girls. ${ }^{16}$

In our study, children treated with CSII reported better metabolic control expressed by lower $\mathrm{HbA1c}$. Similar results were noted in all three age groups. After adjustment for age, sex and diabetes duration, $\mathrm{HbA} 1 \mathrm{c}$ was $0.5 \%$ lower in the CSIl group compared with the MDI group. Both groups of younger children ( $<6$ and $6-<12$ y), using 




B
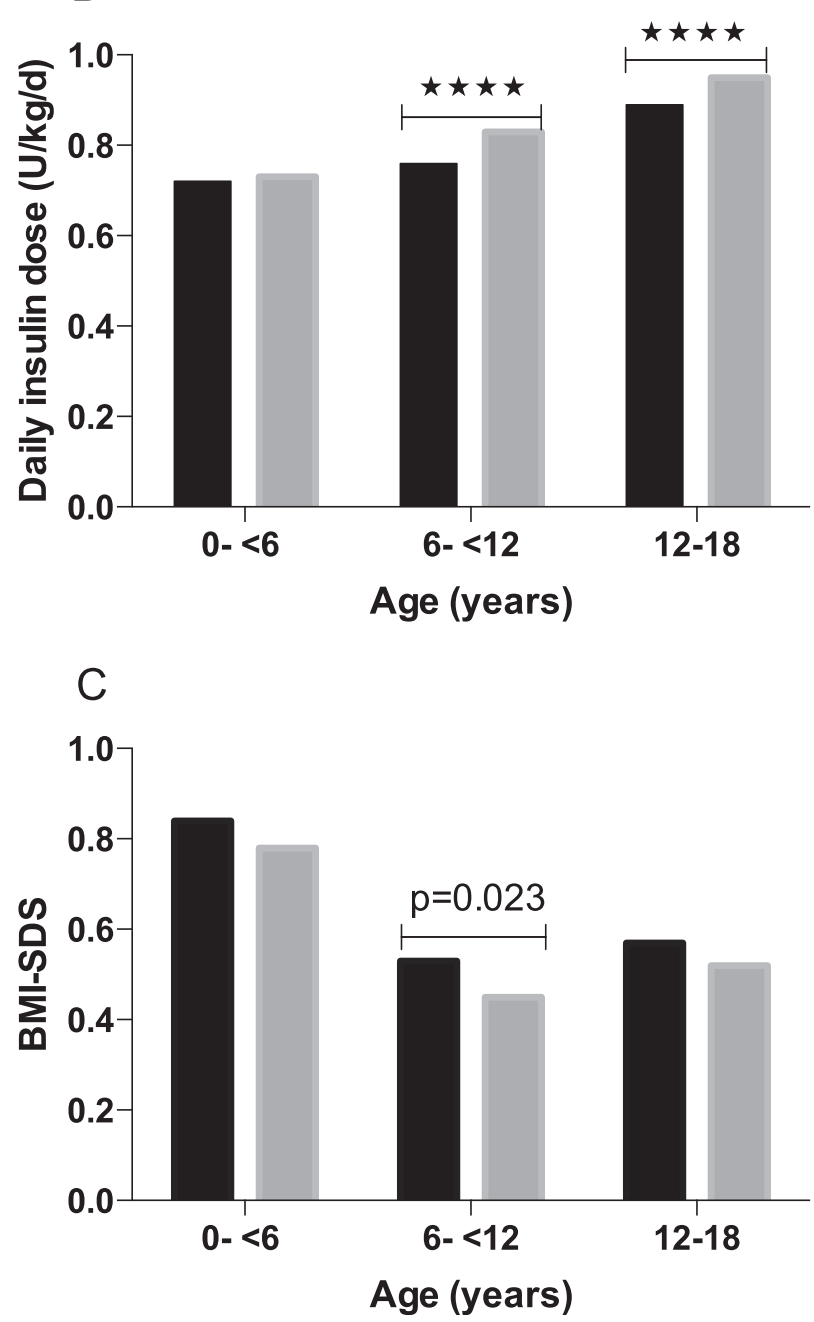

FIGURE 3 Differences between children treated with continuous subcutaneous insulin infusion. ( $\mathrm{CSII}$ ) and multiple daily injections ( $\mathrm{MDI}$ ) in: (A) HbA1c values; (B) daily insulin dose; (C) body mass index standard deviation score (BMI-SDS), ${ }^{* * * *} P<.0001$.

CSII therapy achieved a median $\mathrm{HbA1c}$ value within ISPAD target. Adolescents $>12$-y-old had HbA1c above the ISPAD goal. Despite our data showing better diabetes control in children using CSII therapy, different factors may influence the results, such as patients' selection. In this paper we have not deeply analyzed all factors influencing metabolic control of our patients, therefore our data should be interpreted with caution. The results of analysis comparing CSII and MDI therapy on metabolic control in pediatric population are inconclusive. Similar effectiveness on glycemic control in children using both modalities (CSII and MDI) is shown by some authors ${ }^{28}$ and better metabolic control is noted by others. ${ }^{5}$

In our study the regression analysis showed that children using CSII therapy, had lower insulin dosage and similar BMI-SDS comparing with patients treated with MDI. Flexibility of lifestyle and eating habits in patients using CSII may encourage a greater focus on food intake and cause a weight gain especially in teenagers. Excess weight gain in T1D patients was associated with sustained increases in central obesity, insulin resistance, dyslipidemia, blood pressure, and atherosclerosis. ${ }^{29}$ We report a significant increase in BMI-SDS, only in children aged 6->12 y using CSII; whereas in younger and older patients, no difference was noted between pump users and children using injections.

A limitation of our study is lack of analysis of frequency of hypoglycemia and ketoacidosis between CSII and MDI patients. The group that used CSII included anyone who had been on a pump without a separate analysis depending on the duration of CSII therapy. Furthermore, we have not performed any further analysis concerning influence of some factors such as: work organization, health care service offered by each center or belonging to an ethnic minority, some or all of which may influence frequency and effectiveness of CSII therapy. Another limitation of our study was also not centralized measurement of $\mathrm{HbA1c}$, which may affect the results. However, in order to adjust for differences between laboratories, we use the MOM-Method.

\section{5 | CONCLUSIONS}

Insulin pump therapy is offered by most SWEET centers and is used on average by $44.4 \%$ of patients with comparable percentage of pump users in European and non-European countries. The SWEET centers are a heterogeneous group. The differences among centers for example, the number or age of T1D patients and the national diabetes-related health care expenditure affect the frequency of use of this modern technology. Despite the heterogeneity of centers, T1D children in SWEET achieve good metabolic control; especially those in the younger age groups and those treated with insulin pumps. Further studies evaluating work organization, health care service in each center are needed to identify reversible factors, which may affect diabetes control.

\section{ACKNOWLEDGMENTS}

The authors thank Danièle Pacaud, for her role in the preparation of this article. We would like to thank AstraZenaca for funding this special issue of Pediatric Diabetes. The work of SWEET is possible through the support of the following corporate sponsors: AstraZeneca, Boehringer Ingelheim, DexCom Inc., Diabetes Foundation UK, 
Foundation Hannoversche Kinderheilanstalt, Lilly Diabetes Excellence Center, Medtronic Europe, the Medtronic Foundation, Sanofi.

\section{Funding information}

This research was supported by the AstraZenaca, Boehringer Ingelheim, DexCom Inc. Diabetes Foundation UK, Foundation Hannoversche Kinderheilanstalt, Lilly Diabetes Excellence Centre, Medtronic Europe, Medtronic Foundation, Sanofi.

\section{Author contribution}

Agnieszka Szypowska wrote the manuscript. Stephen MP O'Riordan reviewed and edited the manuscript. Further coauthors researched data und reviewed/edited the manuscript. Anke Schwandt analyzed the data. All coauthors approved the final version to be published.

How to cite this article: Szypowska A, Schwandt A, Svensson J, Shalitin S, Cardona-Hernandez R, Forsander G, Sundberg F, De Beaufort C, Maahs D, Maffeis C, O'Riordan SMP, Krisane ID, Scharf M, Castro S, Konstantinova M, Obermannova B, Casteels K, Gökşen D, Galhardo J, Kanaka-Gantenbein C, Rami-Merhar B, Madacsy L, the SWEET Study Group. Insulin pump therapy in children with type 1 diabetes: analysis of data from the SWEET registry, Pediatr Diabetes 2016, 17 (Suppl. 23), 38-45. DOI:10.1111/ pedi.12416

\section{REFERENCES}

1. Diabetes Control and Complications Trial (DCCT)/Epidemiology of Diabetes Interventions and Complications (EDIC) Study Research Group. Intensive diabetes treatment and cardiovascular outcomes in type 1 diabetes: the DCCT/EDIC study 30-year follow-up. Diabetes Care. 2016;39:686-693.

2. Martin CL, Albers JW, Pop-Busui R; DCCT/EDIC Research Group. Neuropathy and related findings in the diabetes control and complications trial/epidemiology of diabetes interventions and complications study. Diabetes Care. 2014;37:31-38.

3. Fullerton B, Jeitler K, Seitz M, Horvath K, Berghold A, Siebenhofer A. Intensive glucose control versus conventional glucose control for type 1 diabetes mellitus. Cochrane Database Syst Rev. 2014;2:CD009122.

4. Clements MA, Foster NC, Maahs DM, et al. Hemoglobin A1c (HbA1c) changes over time among adolescent and young adult participants in the T1D exchange clinic registry. Pediatr Diabetes. 2015 Jul 8. DOI: 10.1111/pedi.12295. [Epub ahead of print]

5. Danne T, Bangstad H-J, Deeb L, et al. Insulin treatment in children and adolescents with diabetes. Pediatr Diabetes. 2014;15(Suppl. 20):115-134.

6. Johnson SR, Cooper MN, Jones TW, Davis EA. Long-term outcome of insulin pump therapy in children with type 1 diabetes assessed in a large population-based case-control study. Diabetologia. 2013;56:2392-2400.

7. Dovc K, Telic SS, Lusa L, et al. Improved metabolic control in paediatric patients with type 1 diabetes: a nationwide prospective 12-year time trends analysis. Diabetes Technol Ther. 2014;16:33-40.

8. Pickup JC, Sutton AJ. Severe hypoglycaemia and glycaemic control in type 1 diabetes: meta-analysis of multiple daily insulin injections compared with continuous subcutaneous insulin infusion. Diabet Med. 2008;25:765-774.
9. Phillip $\mathrm{M}$, Battelino $\mathrm{T}$, Rodriguez $\mathrm{H}$, et al. Use of insulin pump therapy in the paediatric age-group: consensus statement from the European Society for Pediatric Endocrinology, the Lawson Wilkins Pediatric Endocrine Society, and the International Society for Pediatric and Adolescent Diabetes, endorsed by the American Diabetes Association and the European Association for the Study of Diabetes. Diabetes Care. 2007;30:1653-1662.

10. Renard E. Insulin pump use in Europe. Diabetes Technol Ther. 2010;12(Suppl. 1):S29-S32.

11. American Diabetes Association, European Association for the Study of Diabetes, International Federation of Clinical Chemistry and Laboratory Medicine, International Diabetes Federation. Consensus statement on the worldwide standardisation of the $\mathrm{HbA1c}$ measurement. Diabetologia. 2007;50:2042-2043.

12. World Health Organization. WHO growth reference 5-19 years: BMI-for-age (5-19 years). 2007. http://www.who.int/growthref/ who2007_bmi_for_age/en/index.html. Accessed April 29, 2016.

13. International Diabetes Federation. IDF Diabetes, 7th. Brussels, Belgium: International Diabetes Federation, 2015. http://www. diabetesatlas.org/across-the-globe.html (Accessed March 12, 2016

14. Zhang $P$, Zhang $X$, Brown J, et al. Global healthcare expenditure on diabetes for 2010 and 2030. Diabetes Res Clin Pract. 2010;87:293-301.

15. Miller KM, Foster NC, Beck RW, et al. Current state of type 1 diabetes treatment in the U.S.: updated data from the T1D Exchange clinic registry. Diabetes Care. 2015;38:971-978.

16. Sherr JL, Hermann JM, Campbell F, et al. Use of insulin pump therapy in children and adolescents with type 1 diabetes and its impact on metabolic control: comparison of results from three large, transatlantic paediatric registries. Diabetologia. 2016;59:87-91.

17. Steineck I, Cederholm J, Eliasson B, et al. Insulin pump therapy, multiple daily injections, and cardiovascular mortality in 18,168 people with type 1 diabetes: observational study. BMJ. 2015;350: h3234.

18. Olsen B, Johannesen J, Fredheim S, Svensson J, Danish Society for Childhood and Adolescent Diabetes. Insulin pump treatment; increasing prevalence, and predictors for better metabolic outcome in Danish children and adolescents with type 1 diabetes. Pediatr Diabetes. 2015;16:256-262.

19. Sulmont V, Lassmann-Vague $V$, Guerci B, et al. Access of children and adolescents with type 1 diabetes to insulin pump therapy has greatly increased in France since 2001. Diabetes Metab. 2011;37:59-63.

20. Riemsma R, Corro Ramos I, Birnie R, et al. Integrated sensoraugmented pump therapy systems [the MiniMed ${ }^{\circledR}$ Paradigm $^{\mathrm{TM}}$ Veo system and the Vibe ${ }^{\mathrm{TM}}$ and G4 ${ }^{\circledR}$ PLATINUM CGM (continuous glucose monitoring) system] for managing blood glucose levels in type 1 diabetes: a systematic review and economic evaluation. Health Technol Assess. 2016;20:1-252.

21. Shulman R, Stukel TA, Miller FA, Newman A, Daneman D, Guttmann A. Insulin pump use and discontinuation in children and teens: a population-based cohort study in Ontario, Canada. Pediatr Diabetes. 2016 Jan 8. DOI: 10.1111/pedi.12353. [Epub ahead of print]

22. Lin MH, Connor CG, Ruedy KJ, et al. Race, socioeconomic status, and treatment center are associated with insulin pump therapy in youth in the first year following diagnosis of type 1 diabetes. Diabetes Technol Ther. 2013;15:929-934.

23. Roze S, Smith-Palmer J, Valentine W, de Portu S, Nørgaard K, Pickup JC. Cost-effectiveness of continuous subcutaneous insulin infusion versus multiple daily injections of insulin in type 1 diabetes: a systematic review. Diabet Med. 2015;32:1415-1424.

24. Pickup J. Insulin pumps. Int J Clin Pract Suppl. 2011;170:16-19.

25. Konrad K, Vogel C, Bollow E, et al. Current practice of diabetes education in children and adolescents with type 1 diabetes in Germany and Austria: analysis based on the German/Austrian DPV database. Pediatr Diabetes. 2015 Nov 4. DOI: 10.1111/pedi.12330. [Epub ahead of print]

26. Heinemann L, Fleming GA, Petrie JR, Holl RW, Bergenstal RM, Peters AL. Insulin pump risks and benefits: a clinical appraisal of pump safety standards, adverse event reporting, and research needs: a joint statement of the European Association for the Study of Diabetes and 
the American Diabetes Association Diabetes Technology Working Group. Diabetes Care. 2015;38:716-722.

27. Sulmont V, Souchon PF, Gouillard-Darnaud C, et al. Metabolic control in children with diabetes mellitus who are younger than 6 years at diagnosis: continuous subcutaneous insulin infusion as a first line treatment? J Pediatr. 2010;157:103-107.

28. Golden SH, Brown T, Yeh HC et al. Methods for insulin delivery and glucose monitoring: comparative effectiveness [Internet]. Agency for
Healthcare Research and Quality (US); 2012 July. Report No.: 12EHC036-EF. AHRQ Comparative Effectiveness Reviews.

29. Purnell JQ, Zinman B, Brunzell JD, DCCT/EDIC Research Group. The effect of excess weight gain with intensive diabetes mellitus treatment on cardiovascular disease risk factors and atherosclerosis in type 1 diabetes mellitus: results from the Diabetes Control and Complications Trial/Epidemiology of Diabetes Interventions and Complications Study (DCCT/EDIC) study. Circulation. 2013;127:180-187. 